\section{Práticas de recepção, performatividade de gênero e jornalismo nas eleições de 2018}

Fernanda Nascimento
Recebido em: 12.08.20

Aprovado em: 05.02.21

Fernanda Nascimento

Jornalista, mestra em Comunicação Social (PUCRS) e doutora em Ciências Humanas (UFSC).

E-mail:fn.imprensa@ gmail.com

\title{
Resumo:
}

A cultura da mídia é uma esfera que medeia a construção da realidade e a partir da qual produzimos nossas identidades individuais e coletivas. Neste processo contínuo, também está a produção de performatividades de gênero. No presente artigo, discuto a produção de subjetividades de sapatões, a partir da relação com produtos da cultura da mídia, enfatizando as relações estabelecidas com o jornalismo, no período que envolve as eleições presidenciais de 2018. O estudo de práticas de recepção foi desenvolvido a partir do uso de metodologia de inspiração etnográfica e é alicerçado nos Estudos Culturais e queer. Entre as considerações da investigação estão a mobilização de receios e medos de violência relacionados a um momento de proliferação de discursos e de silêncios, em torno dos gêneros e das sexualidades dissidentes no Brasil, bem como a busca por manejos de visibilidades das experiências sapatões em decorrência do cenário social do país.

Palavras-chave: Mídia. Práticas de Recepção. Sapatões.

\section{Reception practices, gender performance and journalism in the 2018 elections}

\begin{abstract}
:
Media culture is a sphere that mediates the construction of reality and from which we produce our individual and collective identities. In this continuous process, there is also the production of gender performances. In this article, I discuss the production of subjectivities of dykes from the relationship with products of media culture, emphasizing the relationships established with journalism, in the period that involves the presidential elections of 2018. The study of reception practices was developed using ethnographic-inspired methodology and it is based on Cultural and Queer Studies. Among the considerations of the investigation are the mobilization of apprehensions and fears of violence related to a moment of proliferation of discourses and silences around the dissident genders and sexualities in Brazil, as well as the search for management of visibilities of dyke experiences due to the social scenario of the country.
\end{abstract}

Keywords: Media. Reception practices. Dykes. 


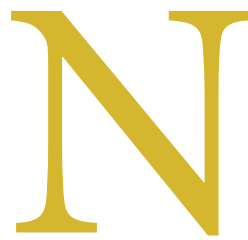

ossas vidas, na contemporaneidade, são saturadas (BIRD, 2003) e colonizadas pelos produtos da cultura da mídia (KELLNER, 2001). Nossas experiências, entendidas como o "processo pelo qual, para todos os seres sociais, a subjetividade é construída" (DE LAURETIS, p. 159, tradução nossa), são compostas por uma miríade de atravessamentos identitários, sociais, culturais e econômicos, sendo necessário que passemos a nos perguntar, como provoca Roger Silverstone, "como a experiência é formada e como a mídia desempenha um papel em sua formação?" (2002, p. 28). Em busca de interpretações que possam contribuir para responder a esta (e outras) questões apresento considerações sobre as relações entre as produções de identidades sapatões e a cultura da mídia, enfatizando as práticas de recepção relacionadas ao jornalismo.

As sapatões, sujeitas desta pesquisa, são interlocutoras marcadas por, pelo menos, uma diferença significativa nos processos de produção das normas sociais: são mulheres que se relacionam afetiva e/ou sexualmente com mulheres. O processo de escuta de suas vozes, a partir da realização de uma pesquisa de inspiração etnográfica, partiu do entendimento de que somos corpos gendrados em um sistema desigual, cujas constantes restrições e interdições produziram proliferações de discursos e silêncios, geralmente emitidos por sujeitos cisgênero ${ }^{1}$ e heterossexuais. Deslocando olhos e ouvidos para compreender histórias, cujos fios se entrelaçam em minha própria identidade, entendo que, como afirma Dafne Patai, "não há vidas sem sentido e não há histórias de vida sem significado. Existem apenas histórias de vida com as quais nós (ainda) não nos preocupamos e cujas revelações (incluindo aquelas de estonteante trivialidade) permanecem-nos, por essa razão, obscuras" (2010, p. 19).

O desenvolvimento deste artigo tem como fundamento a produção de um "pensamento de fronteira" (GROSFOGUEL, 2008). No diálogo entre Estudos Culturais e estudos queer, aliados à inspiração do pensamento descolonial (especialmente o feminismo descolonial), procuro estabelecer uma perspectiva epistêmica capaz de ampliar os cânones ocidentais de pensamento, afetando-se pelas margens e corporificando o conhecimento produzido. Nas palavras de Ramón Grosfoguel, um conhecimento capaz de oferecer "[...] um diálogo crítico entre diversos projetos críticos/políticos/éticos/epistêmicos, apontados para um mundo pluriversal e não para um mundo universal" (2008, p. 117). Inerente à articulação teórica está a escolha por ouvir a voz de pessoas subalternas, uma característica que, infelizmente, não tem sido presente nos estudos desenvolvidos sobre mídias e a população de LGBTIs. Neste artigo, desloco olhos e ouvidos para compreender histórias cujos fios se entrelaçam em minha própria identidade.

\section{Notas teóricas e metodológicas}

A presença significativa da mídia em nossas vidas é inegável. Silverstone define a mídia como "fundamental para a nossa vida cotidiana", sendo uma esfera que "contribui para nossa variável capacidade de compreender o mundo, de produzir e partilhar seus significados" (2002, p. 13). Sendo assim, é uma esfera decisiva na construção de sentidos, estabelecimento de relações de pertencimento e construção de identidades individuais e coletivas. A nossa realidade é mediada e produzida pelas instituições midiáticas, formadas por redes complexas de relações, nas quais as esferas da produção, da recepção e do contexto se articulam. A mídia é um dos espaços pelos quais partilhamos

${ }^{1}$ Que se identificam com o gênero atribuído ao nascimento. significados e parte do processo de construção cultural e social. E é a partir das construções teóricas e metodológicas dos Estudos Culturais que compreendo sua importância social. 
Como gênero, sexualidade e mídia são espaços de construção, significação e ressignificação, as disputas nestes espaços são contínuas. A luta pela hegemonia cultural, "nunca é uma vitória ou dominação pura [...] sempre tem a ver com a mudança no equilíbrio de poder nas relações de cultura" (HALL, 2013, p. 376). Neste jogo de tensionamentos, as receptoras são agentes ativas nas mudanças e continuidades, se apropriando de produtos culturais para construir novos códigos, ressignificando narrativas, propiciando processos de diferenciação difusos.

A reflexão de Elizabeth Bird de que "as imagens e mensagens caem sobre nós, mas a maioria deixa poucos vestígios, a menos que ressoem, mesmo que por um momento, com algo em nossa expectativa pessoal ou cultural" (2003, p. 2, tradução nossa), é um ponto importante para compreender o desenvolvimento deste estudo. Sem me ater a um meio, gênero, produto midiático em específico, investigo as práticas de recepções dos produtos da cultura da mídia de forma irrestrita, buscando compreender as produções de identidades nesta relação. Assim, ao entender que o texto é "apenas um meio" (Ibid, p. 75) e que a mediação da cultura da mídia "não começa nem termina com um texto singular" (SILVERSTONE, 2002, p. 37), analiso as maneiras pelas quais a mídia está "firmemente ancorada na rede da cultura", sendo "articulada pelos indivíduos de diferentes maneiras" (BIRD, 2003, p. 3).

Como estratégia metodológica que pudesse viabilizar o processo de escuta e de interpretação dos sentidos produzidos pelas interlocutoras utilizei como técnicas de pesquisa a entrevista e a produção de diário de campo, ambas desenvolvidas a partir de inspiração da etnografia. Por "inspiração etnográfica" refiro-me ao fato de que recorro às premissas desenvolvidas a partir da etnografia (GEERTZ, 1989) e às problematizações realizadas no campo da antropologia feminista contemporaneamente.

Também utilizo esta inspiração etnográfica na medida em que realizo uma pesquisa que difere de algumas premissas da etnografia clássica, como o distanciamento geográfico ou cultural. Este universo é familiar. Apresenta também o exercício de refletir sobre a alteridade e os processos nessa construção, as relações de poder nas quais o meu corpo também se engendra, as situações de privilégio e opressão, em diferentes espaços.

Ao recorrer às entrevistas tomei como princípio o posicionamento de Nick Couldry sobre a compreensão da voz dos sujeitos como um "[...] processo contínuo de reflexão, trocando narrativas, indo e voltando em nosso passado e presente, entre nós e os outros" (2010, p. 8, tradução nossa). A materialização da presença midiática na articulação de identidades é realizada a partir da linguagem, e escutar as vozes de sujeitas de sexualidade dissidente é romper com uma lógica que privilegia a interpretação realizada por sujeitos dentro da norma.

As entrevistas foram iniciadas com o pedido para que as interlocutoras relatassem suas vidas - sem o estabelecimento de marco ou menção aos produtos da cultura da mídia ${ }^{2}$. A intenção era de perceber a maneira como cada uma era capaz de "[...] articular o mundo a partir de uma posição incorporada distinta" (COULDRY, 2010, p. 8).

Posteriormente, a partir de um roteiro temático, as interlocutoras foram provocadas a refletir sobre aspectos de suas vidas, representações midiáticas ${ }^{3}$ e sobre a política nacional - questão inclusa no roteiro após as contundentes considerações de interlocutoras sobre o impacto eleitoral em suas subjetividades. Na pesquisa doutoral, 17 sujeitas integram o estudo. Neste artigo, um número reduzido de interlocutoras é citado.

As sujeitas do estudo são sapatões que moram em Porto Alegre (RS) e região metropolitana e possuem entre 20 e 35 anos. A "multidão queer" (PRECIADO, 2019) é formada por mulheres entre 20 e 35 anos que se identificam como sapatão, caminhão/caminhoneira, homossexual, lésbica, homoafetiva, gay, LGBT, ovelha colorida da família ou machorra; é branca, morena, meio parda/meio amarela, parda

${ }^{2}$ Proposta inspirada em ESCOSTEGUY, 2013.

${ }^{3}$ Ver percurso metodológico completo em: NASCIMENTO, 2020. 
e café com leite/negra4; oriunda de diferentes classes sociais. Estes atravessamentos perpassam os modos como articulam suas relações com produtos midiáticos, seus interesses, com o que se identificam ou rechaçam ${ }^{5}$.

\section{Performatividade de gênero: corpos em produção}

As relações estabelecidas pelas interlocutoras com os produtos da cultura da mídia foram realizadas, sobremaneira, com o entretenimento. Filmes, novelas, séries, músicas e etc. eram constantemente acionados para mediar diálogos nos quais eram narrados os processos de saída do armário, o reconhecimento de suas identidades, os processos de identificação e diferenciação. Como afirma Kellner: "Não exatamente o noticiário e a informação, mas sim, o entretenimento e a ficção articulam conflitos, temores, esperanças e sonhos de indivíduos e grupos que enfrentam um mundo turbulento e incerto" (2001, p. 32).

Em raras oportunidades o jornalismo foi acionado. As exceções se referiam ao mesmo tema: as eleições presidenciáveis de 2018 e seus desdobramentos. Saliento que encontrei as interlocutoras da pesquisa entre janeiro de 2018 e março de 2019. No período, discussões envolvendo a vida da população LGBTI seguiam mobilizando o noticiário, especialmente em um pleito marcado pela ascensão da pauta contrária ao feminismo e às discussões de gênero, acionada a partir de pânicos morais.

As interlocutoras não passaram incólumes ao processo que adquiriu grande amplitude nos debates e a performatividade de gênero foi utilizada para externar receios consigo ou com as demais. No manejo de visibilidades, a sapatão/caminhão/caminhoneira Larissa ${ }^{6}$ pediu à psiquiatra para ser internada, tamanho medo sentia (DC, 18/1/2019); A sapatão/lésbica Cecília evitou sair às ruas sozinha, temendo hostilidades, "não que eu seja o estereótipo do caminhão, sapatão, mas pelo cabelo curto, raspado" e pensou em deixar os cabelos crescerem, assim como as amigas haviam adotado o uso de saias tentando se distanciar de uma identificação da sexualidade dissidente (DC, 8/1/2019); Aline, sapatão, pediu demissão e disse não suportar os comentários relacionados ao tema (DC, 7/1/2019).

Valentina contou ao pai, eleitor de Bolsonaro, que é sapatão e que tinha medo de andar na rua com a namorada e ouviu de amigos a advertência de que "agora tem que deixar o cabelo crescer" (23/3/2019); Sua namorada, Rafaela, seguiu com

${ }^{4}$ Autoidentificações oriundas do campo e problematizadas em NASCIMEN-

TO, 2020. Os termos e expressões em itálico são oriundos do campo.

${ }^{5}$ Uma discussão aprofundada sobre as categorias nativas e analíticas e os processos de produção de si está presente em NASCIMENTO, 2020.

${ }^{6}$ Pseudônimos. Para mais informações sobre as características das interlocutoras ver:

NASCIMENTO, 2020.

${ }^{7}$ Mayara me afirmou que acreditava não poder votar por possuir dívidas contestadas. os mesmos cuidados de sempre, afinal "ser mulher é ser vulnerável para qualquer tipo de agressão" (23/3/2019); A lésbica/gay Sabrina receou pelas demais, afinal, nas palavras dela: "eu, Sabrina, quem vai dizer que eu sou gay? Ninguém vai dizer que eu sou gay" (DC, 11/2/2019). E estabeleceu uma relação entre nós, "tu tem cabelo curto, com certeza vai ser mais julgada que eu", e entre os demais amigos "é mais fácil homem que é extremamente gay [ser agredido]"(DC, 11/2/2019); Mayara, caminhão/caminhoneira/sapatão, não votou porque "tem o nome sujo no Serasa", mas teria escolhido o candidato Jair Bolsonaro, pois "dos outros que eu vi, ele tinha mais punho forte" (9/2/2019); Kauanê relatou ter medo pela ex-esposa e pelas amigas, já que "pode andar na rua tranquilo que ninguém diz que sou sapatão" e quase chorou relembrando a apuração do segundo turno eleitoral: "A minha ex-esposa começou a chorar baixinho e eu disse 'vai ficar tudo certo' e ela olhou pra mim e disse 'tá, olha pra mim', ela só disse isso, 'olha pra mim'. Aquilo me matou. Ela é um alvo fácil [...]. Está na testa que ela é sapatão” (DC, 6/2/2019).

A performatividade de gênero das interlocutoras é elemento central para compreender os receios. É desde a inteligibilidade de um corpo dentro ou fora das normas que são concedidos benefícios ou distribuídas consequências. Todas as interlocutoras possuem sexualidades dissidentes e sofrem sanções por essa transgressão. Mas, a materialização de gênero e sexualidade nos corpos é distinta.

Em decorrência das limitações de espaço não desenvolverei uma ampla discussão sobre o conceito de performatividade de gênero, mas considero im- 
portante pontuar que as análises são desenvolvidas desde uma perspectiva dos estudos queer, especialmente em diálogo com Judith Butler, Gayle Rubin, Paul Preciado, Jack Halberstam.

Nas fronteiras borradas de uma existência negociada, as construções e as produções de gênero das interlocutoras da pesquisa se relacionam de diferentes formas com as categorias "mulher", "lésbica", "sapatão", "masculino", "feminino". A materialização dos corpos é construída por diversos fatores, pelas expressões que designam e diferenciam identidades. São produções de identidades sexuais gendradas, significativas, porque a "experiência subjetiva da vida sexual é compreendida [...] como um produto dos símbolos e significados intersubjetivos associados com a sexualidade, em diferentes espaços sociais e culturais" (PARKER, 2000, p. 103).

Nas disputas envolvendo o conceito de gênero, uma proposição significativa é a compreensão desta categoria como "um modo primeiro de significar as relações de poder" (SCOTT, 1995, p. 86), marcadamente históricas e contextuais. Nesta posição está implicada a compreensão de que masculino não é sinônimo de homens e tampouco de que feminino seja sinônimo de mulheres. Feminilidades e masculinidades extravasam os corpos e organizam a sociedade.

Compreendo que, tal como postula Butler, não apenas o gênero é construído, mas o próprio sexo. $\mathrm{Na}$ "[...] verdade, talvez o sexo tenha sido desde sempre gênero, de maneira que a distinção sexo/gênero não é, na verdade, distinção alguma" (2013, p. 7). Se a linguagem é fundamental no processo de produção do gênero, a materialidade de masculinidades e feminilidades se dá em corpos sexuados. Ao mesmo tempo, os corpos gendrados carregam consigo concepções de humanidade (ou ausência dela), atravessadas pelo processo de racialização que marca a colonialidade de gênero (LUGONES, 2014). São também corpos nos quais o posicionamento de classe interfere na possibilidade de distintos controles do gênero e da sexualidade. Para Jeffrey Weeks, "os corpos não têm nenhum sentido intrínseco" e a "melhor maneira de compreender a sexualidade é como um construto histórico" (2000, p. 36). Butler considera o corpo "não como uma superfície pronta à espera de significação, mas como um conjunto de fronteiras individuais e sociais, politicamente significadas e mantidas" (2013, p. 59).

O gênero é produzido em determinados contextos, a partir da reiteração de atos, o que não significa que esta construção é autônoma e voluntarista. Os sujeitos não possuem total autonomia para realizar movimentos deliberados. Ao contrário, seus limites estão definidos desde o princípio. "É uma atuação coercitiva no sentido de que essa ação fora das normas heterossexuais gera o ostracismo, a punição e a violência, sem mencionar os prazeres transgressores produzidos pelas mesmas proibições" (BUTLER, 2000, p. 102, grifos da autora, tradução nossa)

A reiteração sistemática de normas, anteriores ao sujeito, é capaz de materializar práticas marcadas pela regulação. A ausência de problematização destes processos faz com que as imposições que acontecem a partir da performatividade de gênero a tornem natural. Esta produção é materializada pela linguagem. É nos sistemas de classificação e categorização que a performatividade torna-se inteligível. Mantemo-nos na matriz da inteligibilidade de gênero a partir da linguagem que nomeia os corpos. Como afirma Butler “[...] 'as pessoas' só se tornam inteligíveis ao adquirir seu gênero em conformidade com padrões reconhecíveis de inteligibilidade de gênero" (2013, p. 37).

A inteligibilidade adquirida pela linguagem não significa que a materialidade exista por si só, tampouco que os corpos sejam puramente discursivos. Como afirma Weeks, "é através do corpo que experimentamos tanto o prazer quanto a dor" (2000, p. 43). Para Paul Preciado, "o gênero é, antes de tudo, prostético, ou seja, não se dá senão na materialidade dos corpos. É puramente construído e ao mesmo tempo inteiramente orgânico. [...] O gênero poderia resultar em uma tecnologia sofisticada que fabrica corpos sexuais" $(2014$, p. 29). 
Os processos de diferença analítica estão presentes nas formas pelas quais expressões de gênero adquirem importância ou tornam-se abjetos. As sujeitas estabelecem relações desde um lugar marcado pela circulação de sentidos, que estratificam e organizam as relações sociais.

Na medida em que a negociação com masculinidades em mulheres é significativa para o campo e destoa das normas de gênero estabelecidas socialmente, considero importante pontuar que, como afirma Sam Bourcier, sapatão refere-se a "uma identidade de gênero muito mais do que uma identidade sexual" (2015, p. 51). E estes repertórios de feminilidades ou masculinidades em mulheres (HALBERSTAM, 2008) são acionados nos receios das interlocutoras ao falarem sobre suas vidas no período analisado.

\section{Performatividade de gênero e jornalismo}

Os receios das interlocutoras sobre suas performatividades vinham amparados em uma série de notícias (e fake news), envolvendo o processo eleitoral e seus desdobramentos. Destaco as considerações de três interlocutoras sobre o tema.

Daiana se define como alguém bem padrão: não era uma criança sapatão, mas desde cedo aprendeu que não poderia virar machorra. Cabelos na altura dos ombros, roupas despojas, maquiagem e acessórios. Ela acredita só ser percebida como lésbica quando acompanhada da namorada e expressando afeto em público. Autoidentificada como branca, 21 anos, estudante de Sociologia, bolsista de iniciação científica, moradora do bairro Ipanema, na zona Sul de Porto Alegre, distante $17 \mathrm{~km}$ do centro da Capital. Daiana tem uma experiência de moradia em casas confortáveis, em diferentes cidades por onde os pais se deslocaram para trabalhar. Estudante de escola particular e com uma criação que prezava pelo acesso a bens culturais, não esperava a reação do pai (antropólogo) ao contar sobre a sexualidade. Ouviu que o interesse por outras mulheres era uma fase passageira (DC, 17/1/2019).

No manejo de visibilidades que sua performatividade permite, não esconde a sexualidade, mas não tem certeza se quando concluir a faculdade irá chegar falando que é lésbica para seus colegas e alunos.

Daiana que disse que chorou muito, especialmente entre os dois turnos. "Na transição [de governo], não paravam de aparecer notícias, lembra da guria que cravaram uma suástica? Isso não parava de aparecer. Eu nunca tinha tido crise de pânico na vida e eu tive. Depois que li a suástica, tive uma crise. Sabendo que eu não sou lida como lésbica, eu não tava correndo tanto risco, me preocupo com minhas amigas, namorada, tranquei redes sociais, fiquei 'noiada', agora tô mais tranquila, já tá vindo menos notícias". Pergunto se ela tem medo de ser agredida na rua. "Tenho mais medo de estupro do que de agressão física. Tenho medo de estupro corretivo. Acho que cometem mais agressões contra homens gays ou lésbicas que não são femininas", avalia. Pergunto se ela deixou de ir a algum lugar. "Deixei de sair, não saía mais, parei de andar adesivada, só panfletava com mais gente" (DC, 17/1/2019).

Andressa, cabelos compridos e amarrados, camiseta, calça jeans e tênis. A mãe sempre disse que ela se vestia meio estranha, mas ao sair do armário garantiu à progenitora que não iria "aparecer com cabelo curto e calça larga" (DC, 6/2/2019). Autoidentificada como meio parda, meio amarela, com 22 anos, cresceu e mora com a mãe e a irmã em uma casa no bairro Mathias Velho, em Canoas (RS), cursa Psicologia e trabalha como auxiliar de administração. A localidade periférica da região metropolitana onde mora é a mais populosa do município, distante $25 \mathrm{~km}$ do centro de Porto Alegre.

Nas estratégias para fugir de situações constrangedoras relacionadas ao gênero e a sexualidade, assume posições ambíguas: quando trabalhava como secretária vestia-se bem sapatão para evitar assédio; porém, por mais que acredite ser meio visível que é sapatão, em algumas situações, prefere omitir a sexualidade. 
Comento que ela falou que agora estava mais difícil ser LGBTI e que imaginei que ela falasse do período eleitoral. Ela concorda e diz que chorou ao ver o resultado das eleições e teve uma crise de ansiedade, ficava só pensando: "meu deus, vou morrer". Andressa me diz que a mãe a apavorou muito e que não a deixou participar de manifestações, porque antes dos atos ouviu uma notícia sobre meninas espancadas. Andressa me diz que aconteceram casos de pessoas espancadas em Canoas que foram noticiados. Ela diz que os únicos atos políticos que participa são as "paradas gays", mas que a mãe "sempre monitora" com medo do que pode acontecer, "mesmo assim eu vou" (DC, 6/2/2019).

Já Laura, branca, visual hippie, roupas largas, cabelos na altura dos ombros e desgrenhados, acredita percorrer a cidade praticamente incólume, porque considera seu visual mais alternativo, afinal, aqui [Porto Alegre] as meninas se vestem assim. O único problema que percebe em sua performatividade é que tem pelos demais nas pernas. Quando viajou para Santana do Livramento, cidade natal e na qual vive a família dos pais, decidiu se depilar, para evitar maiores conflitos.

Autoidentificada como branca, com 20 anos, a estudante de Ciências Sociais e moradora do bairro Tristeza - próximo a Ipanema, onde reside Daiana. É oriunda de uma família formada por uma mãe artista plástica e o pai contador/fazendeiro, e frequentou escolas particulares e teve acesso a bens culturais que ela mesma classifica como exceção. Depois da separação dos pais, passou a morar com a vó.

Em Porto Alegre, "escondeu-se" em apenas uma oportunidade: durante o processo eleitoral. "Comecei a esconder os pelos, eu tinha medo, sei lá" (DC, 28/1/2019). Outra consequência do período eleitoral foi a saída das redes sociais. O motivo: a quantidade de notícias sobre o tema estava gerando crise de ansiedade.

Os sentimentos de angústia e aflição fizeram com que saísse das redes sociais havia dois meses, evitando ler notícias sobre política ou comentários a respeito do tema. Laura me diz que também vê 'muita informação inútil' e já tem 'problemas demais na vida nesse momento' para ficar acompanhando tudo (DC, 28/1/2019).

O jornalismo é uma das esferas de construção social da realidade (BERGMAN; LUCKMANN, 2004) e, como produtor de sentidos, é uma das maneiras pelas quais se produzem percepções sobre a realidade, extremamente relacionados ao senso comum (MEDITSCH, 1997). Como afirmam Peter Berger e Thomas Luckmann, "minha interação com os outros na vida cotidiana é por conseguinte constantemente afetada por nossa participação comum no acervo social disponível de conhecimento" (2004, p. 62).

O "acervo social disponível de conhecimento" do processo eleitoral e pós-eleitoral de 2018 é marcado por discussões em torno dos gêneros e sexualidades dissidentes. Notícias e fake news sobre o tema foram promovidas, sobremaneira, por sujeitos ligados a setores conservadores. Compreendo a ofensiva como uma reação contrária aos avanços progressistas das duas últimas décadas. Como afirma Miskolci, "os pânicos morais exprimem de forma culturalmente complexa as lutas sobre o que a coletividade considera legítimo em termos de comportamento e estilo de vida" (2007, p. 111).

Em uma eleição marcada pela disseminação massiva de fake news, a Agência Lupa identificou que os boatos em torno do projeto Escola Sem Homofobia, chamado pelos detratores de "kit-gay", foram as que obtiveram "mais compartilhamento de modo difuso, já que foram divulgados em formatos diversos - vídeos, fotos e notícias falsas" (LIBÓRIO; CUNHA, 2018, s/n). Dentre os 15 maiores boatos eleitorais, seis estavam relacionados às sexualidades dissidentes e aos pânicos morais.

Parte das fake news já circulavam desde 2011, ano lançamento do Escola Sem Homofobia. Fernando Balieiro identifica este momento como crucial para a compreensão da ofensiva conservadora - ocorrida, não por acaso, na mesma semana em que o STF reconheceu a união estável entre homossexuais. "Em resposta, um pânico moral foi criado a partir da promoção de uma campanha sobre a suposta nocividade do material para as crianças" (2018, p. 54). 
Entre 2011 e 2018, é possível enumerar uma série de situações limites nos quais a defesa da infância e o combate à "ideologia de gênero" estiveram no cerne do debate político: consolidação do Movimento Escola Sem Partido; fechamento da exposição Queermuseu; perseguição à teórica Judith Butler etc. As "políticas do sexo" (RUBIN, 2017) estiveram presentes de forma significativa nos debates e as subjetividades foram amplamente discutidas.

Os temores e receios das interlocutoras sobre suas vidas ou daqueles que as cercavam estão relacionados aos efeitos cumulativos (KELLNER, 2001) de uma produção noticiosa a respeito do tema. Os corpos estiveram no centro do debate, impactados pelo debate social. Como afirmam Gislene da Silva e Rosana de Lima Soares, as produções de sentido do jornalismo contribuem para "[...] responder as demandas mais subjetivas, aquelas que a partir desse capital social de conhecimento, constituído na e pela linguagem, interpelam diretamente os sujeitos em suas relações consigo mesmos e com os outros" (2011, p. 195).

A sensação de violência das interlocutoras não estava descolada nem das notícias, tampouco de um movimento mais amplo. De acordo com pesquisa da Gênero e Número, 92,5\% dos LGBTIs perceberam uma escalada de ódio após o processo eleitoral. A pesquisa aponta que $94 \%$ dos LGBTIs sofreram agressões verbais e $13 \%$ físicas. Lésbicas e transexuais eram os mais vulneráveis. Em outubro de 2018, o Disque 100 recebeu 330 denúncias de violência contra LGBTIs, um aumento de 272\% em relação ao mesmo período de 2017 (PREITE SOBRINHO, 2019, s/n).

Uma das notícias com maior repercussão do período, citada por Daiana, foi a informação de que uma jovem de 19 anos teria sido atacada por três homens e tido a barriga marcada com um símbolo semelhante a uma suástica, em Porto Alegre. O episódio teria ocorrido um dia após o primeiro turno eleitoral e a jovem sustentou motivação homofóbica, por manifestar-se contra Jair Bolsonaro com adesivos identificados com o movimento LGBTI.

O caso foi amplamente noticiado. A jovem registrou boletim de ocorrência e realizou exame de corpo de delito. Câmeras de segurança da região não registraram a suposta agressão e o fato do laudo técnico do Instituto Geral de Perícias afirmar a inexistência de resistência diante das agressões fez com que a polícia concluísse o inquérito e a indiciasse por falsa comunicação de crime. A jovem retirou a denúncia alegando questões emocionais, mas a defesa sempre sustentou que a desistência e o laudo não significavam confissão de culpa, já que a ausência de resistência não é incomum em casos de estresse traumático, além do desgaste emocional. O caso foi encerrado com um acordo e ao invés de responder judicialmente por falsa acusação de crime, ela concordou em realizar serviços à comunidade.

Eduardo Meditsch (1997) defende o conceito de jornalismo como uma forma de conhecimento, especialmente relacionada com o senso comum. $\mathrm{O}$ jornalismo é uma das maneiras pelas quais as interlocutoras conhecem a realidade. E, como afirma Traquina,"[...] é impossível estabelecer uma distinção radical entre a realidade e os media noticiosos que devem 'refletir' essa realidade, porque as notícias ajudam a construir a própria realidade" (TRAQUINA, 2005, p. 168).

Nenhuma das interlocutoras sofreu violências físicas durante o período eleitoral, mas quase todas se sentiram inseguras e intimidadas porque havia uma circulação de informações sobre o aumento da violência, não apenas por antagonismos em torno de posições políticas diferentes, mas porque seu gênero e sexualidade estavam no cerne do debate público. É importante destacar que, por mais que as notícias e fake news relacionadas às questões de gênero e sexualidade afirmassem realizar uma "defesa da infância", essa defesa só poderia ser feita desde que houvesse alguém a atacando. Ou seja, LGBTIs eram, em potencial, responsáveis pelos ataques contra a inocência infantil. Como afirma Balieiro, a estratégia de utilizar a ameaça às crianças foi capaz de ocultar "posicionamento restritivo às diferenças" (2018, p. 62), utilizando como método a disseminação de pânicos morais. 
Essas informações circularam de diferentes formas ao longo dos anos e durante a cobertura eleitoral. Mas é possível afirmar que foi especialmente a partir dos noticiários políticos que adquiriram repercussão. Com uma proliferação de informações apuradas ou de mentiras produzidas, os temas adquiriram proeminência e se tornaram decisivos, a ponto de gerar medo, ansiedade e, como foi possível analisar, mobilizaram reflexões sobre a performatividade de gênero. $\mathrm{O}$ medo de violência contra si, ou contra as que a cercavam, era especialmente atravessado pela performatividade de gênero. Era o medo da mãe de Andressa sobre a filha, o receio de Daiana sobre as outras e o que motivou Laura a mudar o comportamento. Era o receio das demais que não citavam notícias, mas que, possivelmente as acessaram a partir de diferentes meios. É possível refletir se, o fato de o jornalismo trabalhar a partir do factual e se construir desde a lógica do senso comum, contribui para que essa circulação e sua importância em nossas relações cotidianas faça o contato com seus conteúdos mais imperceptível na comparação com produtos de entretenimento.

Os conhecimentos que circularam antes e durante o processo eleitoral, construindo um contexto de violência, fez com que temores que já perpassavam a existência das interlocutoras da pesquisa acionassem medos atravessados pelas performatividades de gênero. Os receios estão diretamente relacionados a uma performatividade mais ou menos enquadrada dentro da norma e às possibilidades de manejo das visibilidades dos corpos nas ruas

\section{Considerações}

As eleições presidenciais de 2018 no Brasil impactaram as formas como as interlocutoras se colocam no mundo. Transformaram as preocupações e receios pela integridade de suas vidas e/ou daquelas com quem compartilham sonhos e esperanças, justamente pela centralidade de seus corpos na agenda das regulações de gênero e sexualidade discutida publicamente.

A circulação de notícias contribuiu para a ampliação do medo de agressões. O jornalismo contribuiu para criar o "acervo social disponível de conhecimento" (BERGMAN; LUCKMANN, 2004, p. 62) do período. Se "concretamente, muito pouco se sabe sobre os efeitos do Jornalismo sobre os indivíduos ou as sociedades" (MEDITSCH, 1997, p. 11), justamente pelo fato de ser caracterizado por um trabalho com o factual e se construir a partir da lógica do senso comum, foi possível interpretar que essa esfera cumpriu uma função significativa na experiência das interlocutoras, nesse momento decisivo.

Como afirma Kellner: "[...] os meios dominantes de informação e entretenimento são uma fonte profunda e muitas vezes não percebida de pedagogia cultural: contribuem para nos ensinar como nos comportar e o que pensar e sentir, em que acreditar, o que temer e desejar - o que não" (2001, p. 10). E elas, desde cedo, compreenderam as diferenças entre uma passabilidade cisheterossexual, construída a partir de elementos como o comprimento de cabelos, uso de determinados adereços, circulação por espaços etc. e as diferenças entre as masculinidades nos corpos de mulheres.

Mais do mobilizar suas discussões e debates, as notícias e fake news envolvendo gênero e sexualidade foram capazes de mediar manejos de visibilidades das interlocutoras, destacando a importância da mídia na produção constante das visibilidades e, neste caso, especialmente das performatividades.

O fato do jornalismo raramente ter sido citado pelas interlocutoras não significa que a esfera seja menos importante em suas vidas, mas que possivelmente seus conhecimentos atrelados ao senso comum passem despercebidos, sendo destacados em momentos decisivos de suas vidas. Assim, o jornalismo, esfera construtora e mediadora da realidade foi responsável por mobilizar conflitos e tensões que perpassavam o tecido social e implicavam diretamente na produção das identidades sapatões. 


\section{Referências}

BALIEIRO, Fernando. "Não se meta com meus filhos": a construção do pânico moral da criança sob ameaça. Cadernos Pagu, Campinas, n. 53, 2018. Disponível em: encurtador.com.br/rwC36. Acesso em 2 nov. 2019.

BERGMAN, Peter.; LUCKMANN, Thomas. A construção social da realidade. Petrópolis: Vozes, 2004.

BIRD, Elizabeth. The audience in everyday life: Living in a media world. Nova York/Londres: Routledge, 2003.

BOURCIER, Sam. Uma conversa franca com MH/Sam Bourcier sobre correntes feministas e queer na contemporaneidade. Revista Feminismos, v.3, n.2/3, p.48-59, 2015.

BUTLER, Judith. Problemas de gênero: feminismo e subversão da identidade. Rio de Janeiro: Editora Civilização Brasileira, 2013.

BUTLER, Judith. Imitación e insubordinación de género. Revista de Occidente, $\mathrm{n}^{\circ}$ 35, p.85-109, 2000. Disponível em: encurtador.com.br/sBQR6. Acesso em 22 set. 2019.

COULDRY, Nick. Why voice matters: culture and politics after neoliberalism. London: Sage, 2010.

DE LAURETIS, Teresa. Tecnologia de gênero. In: BUARQUE DE HOLLANDA, Heloisa (Org.). In: Pensamento feminista: Conceitos fundamentais. Rio de Janeiro: Bazar do Tempo, 2019. p. 121-155.

ESCOSTEGUY, Ana Carolina. Melodrama e heroicização: a mídia no relato biográfico. Matrizes, São Paulo, v.2, n.2, p.143-159, 2013. Disponível em: encurtador. com.br/fnSW5. Acesso em 25 out. 2017.

GEERTZ, Clifford. A interpretação das culturas. Rio de Janeiro: Editora Guanabara Koogan, 1989.

GROSFOGUEL, Ramón. Para descolonizar os estudos de economia política e os estudos pós-coloniais: Transmodernidade, pensamento de fronteira e colonialidade global. Revista Crítica de Ciências Sociais, Coimbra, n. 80, p.115-147, mar. 2008. Disponível em: http://journals.openedition.org/rccs/697. Acesso em: 12 mai. 2016.

HALBERSTAM, Jack. Masculinidad feminina. Barcelona: Egales Editorial, 2008.

HALL, Stuart. Da diáspora: Identidades e mediações culturais. Belo Horizonte: Editora UFMG, 2013.

KELLNER, Douglas. A cultura da mídia: Estudos Culturais: identidade e política entre o moderno e o pós-moderno. Bauru: EDUSC, 2001.

LIBÓRIO, Barbara; CUNHA, Ana Rita. Notícias falsas foram compartilhadas ao menos 3,84 milhões de vezes durante as eleições. Aos Fatos, São Paulo, 31 out. 2018. Disponível em: encurtador.com.br/oVYZ6. Acesso: 22 nov. 2019.

LUGONES, Maria. Rumo a um feminismo descolonial. Revista Estudos Femi- 
nistas, Florianópolis, v. 22, n.3, p.935-952, set. 2014. ISSN 1806-9584. Disponível em: https://periodicos.ufsc.br/index.php/ref/article/view/36755. Acesso em: 17 jul. 2018.

MEDITSCH, Eduardo. O jornalismo é uma forma de conhecimento? Media \& Jornalismo, n.1, p. 9-22, 2002.

MISKOLCI, Richard. Pânicos morais e controle social: reflexões sobre o casamento gay. Cafajeste. Cadernos Pagu, Campinas, n. 28, p.101-128, junho 2007.

MISKOLCI, Richard; CAMPANA, Maximiliano. "Ideologia de gênero": notas para a genealogia de um pânico moral contemporâneo. Revista Sociedade e Estado, v.32, n.3, p.725-745, setembro/dezembro 2017.

NASCIMENTO, Fernanda. Sapatões e mídia: produções de identidades a partir de práticas de recepção. Tese (Doutorado), 261f. Programa Interdisciplinar em Ciências Humanas, Universidade Federal de Santa Catarina, Florianópolis, 2020.

PARKER, Robert. Cultura, economia política e construção social da sexualidade. IN: LOURO, Guacira Lopes (Org.). O corpo educado: pedagogias da sexualidade. Belo Horizonte: Autêntica, 2000, p. 125-150.

PATAI, Daphne. História oral, feminismo e política. São Paulo: Letra e Voz, 2010.

PRECIADO, Paul. Multidões queer: notas para uma política dos "anormais". In: HOLLANDA, Heloisa Buarque de (Org.). Pensamento feminista: Conceitos fundamentais. Rio de Janeiro: Bazar do Tempo, 2019. p. 397-409.

PRECIADO, Paul. Manifesto contrassexual: práticas subversivas de identidade sexual. São Paulo: n1 edições, 2014.

PREITE SOBRINHO, Wanderley. Brasil registra uma morte por homofobia a cada 16 horas, aponta relatório. UOL, São Paulo, 20 fev. 2019. Disponível em: encurtador.com.br/oqvxJ. Acesso: 22 nov. 2019.

RUBIN, Gayle. Políticas do Sexo. São Paulo: Ubu Editora, 2017.

SCOTT, Joan. Gênero: uma categoria útil de análise histórica. Educação e Realidade, v.20, n.2, p.71-79, 1995. Disponível em: encurtador.com.br/dgmrN. Acesso em 9 out. 2016.

SILVA, Gislene; SOARES, Rosana de Lima. Da necessidade e da vontade de se consumir notícia. Comunicação, mídia e consumo, São Paulo: ano 8, vol.8, n.23, p.181-198, nov. 2011.

SILVERSTONE, Roger. Por que estudar a mídia? São Paulo: Loyola, 2002.

TRAQUINA, Nelson. Teorias do jornalismo, porque as notícias são como são. Florianópolis: Insular, 2005

WEEKS, Jefrey. O corpo e a sexualidade. IN: LOURO, Guacira Lopes (Org.). O corpo educado: pedagogias da sexualidade. Belo Horizonte: Autêntica, 2000, p.35-82. 